\title{
Reflexões sobre o processo de licenciamento ambiental em empreendimentos no Estado de Sergipe
}

A Lei $6.938 / 81$ foi criada para ser um mecanismo de controle ambiental comum dos entes federativos e que rege a política ambiental do país. $O$ licenciamento ambiental é um dos mecanismos mais importantes, pois é através dele que o Poder Público estabelece condições e limites ao exercício de determinada atividade econômica para que seja minimizada a degradação ambiental. Este trabalho teve como objetivo discutir teoricamente o processo do licenciamento ambiental em empreendimentos no estado de Sergipe pautado na legislação estadual.

Palavras-chave: Direito Ambiental; Legislação; Licenciamento Ambiental; Sergipe.

\section{Reflections on the environmental licensing process in enterprises in the State of Sergipe}

The Law 6.938 / 81 was created to be a mechanism of common environmental control of federative entities and that governs the country's environmental policy. Environmental licensing is one of the most important mechanisms, since it is through it that the Public Power establishes conditions and limits to the exercise of a certain economic activity so that environmental degradation is minimized. This work aimed to discuss theoretically the process of environmental licensing in enterprises in the state of Sergipe under the state legislation.

Keywords: Environmental Law; Legislation; Environmental Licensing; Sergipe.

Topic: Legislação e Direito Ambiental

Reviewed anonymously in the process of blind peer
Received: 05/02/2019

Approved: 10/04/2019
Cecílio Sergio Vieira Gomes Júnior

Centro Universitário Maurício de Nassau, Brasil

http://lattes.cnpq.br/7022905054637596

csvgj22@gmail.com

\section{Carlos Eduardo Silva}

Centro Universitário Maurício de Nassau, Brasil

http://lattes.cnpq.br/3700554054159220

http://orcid.org/0000-0001-8358-0263

scientiasilva@gmail.com
Referencing this:

GOMES JÚNIOR, C. S. V.; SILVA, C. E.. Reflexões sobre o processo de licenciamento ambiental em empreendimentos no Estado de Sergipe. Naturae, v.1, n.1, p.1-11, 2019. DOI: http://doi.org/10.6008/CBPC2674-6441.2019.001.0001 


\section{INTRODUÇÃO}

As discussões sobre as questões ambientais na sociedade brasileira tornaram-se mais relevantes nas últimas décadas, e consequentemente, cotidianamente são debatidas nos meios acadêmicos, mídias e redes sociais. A sociedade passa a perceber com maior clareza como a gestão dos recursos naturais podem comprometer ou garantir a sustentabilidade. Estas consequências podem ser percebidas diariamente nas cidades ou no campo (BRASIL, 2009).

O contexto citado acima surgiu no século XX especificamente na década de 60 no qual o debate sobre a preservação ambiental se tornou necessária, o que ocasionou mobilização de congressos nacionais e internacionais com o objetivo de aliar o desenvolvimento econômico e a sustentabilidade dos recursos naturais considerando que o sistema econômico prevalecente é o capitalismo que compreende ser um sistema econômico pautado na ampliação dos lucros (SOBRINHO, 2016).

Visto que durante muitos anos, desde a Revolução Industrial, os benefícios econômicos suplantaram os males causados ao meio ambiente e à sociedade como um todo. Foi em 1968, com o advento do Clube de Roma, que educadores, políticos, economistas, cientistas e empresários levantaram a polêmica das questões ambientais. Os principais problemas apontados pelo documento de maior repercussão do Clube de Roma, de acordo com o Relatório Meadows, foram: (a) industrialização acelerada; (b) rápido crescimento demográfico; (c) escassez de alimentos; (d) esgotamento de recursos não renováveis; (e) deterioração do meio ambiente.

As questões socioambientais não tinham prioridade perante as questões econômicas, especialmente nas nações com processos de desenvolvimento mais ativo. Somente em 1969, surgiu a primeira manifestação institucionalizada de política relacionada aos impactos ao meio ambiente, com a criação do NEPA (National Environmental Policy Act), nos EUA, que no ano seguinte determinou o surgimento do processo de Avaliação de Impacto Ambiental (AIA).

A AIA versava sobre os objetivos e princípios da política ambiental norte-americana, obrigatório para empreendimentos com potencial impactante, e era composto pelos seguintes itens: (a) identificação dos impactos ambientais; (b) efeitos ambientais negativos da proposta; (c) alternativas da ação; (d) relação dos recursos ambientais negativos no curto prazo e a manutenção ou mesmo melhoria do seu padrão no longo prazo; (e) definição clara quanto a possíveis comprometimentos dos recursos ambientais para o caso de implantação da proposta.

A aplicação da AIA generalizou-se rapidamente nos Estados Unidos, tendo em vista a força da NEPA e das legislações estaduais afins, assim como em outros países desenvolvidos e, pouco mais tarde, junto aos países em desenvolvimento. Tempos após de sua consolidação, este modelo foi adotado pela França, Canadá, Holanda, Grã-Bretanha, Alemanha e outros. Mesmo em locais onde a AIA não está prevista na legislação, este instrumento tem sido aplicado por força das exigências de organismos internacionais. 
Atualmente, fazem uso da Avaliação de Impactos Ambientais, todos os principais organismos de cooperação internacional, como os órgãos setoriais da Organização das Nações Unidas (ONU), o Banco Mundial (BIRD), o Banco Interamericano de Desenvolvimento (BID), entre outros.

No Brasil, as primeiras tentativas de aplicação de metodologias de avaliação foram decorrentes de pressão por parte de organismos financeiros internacionais sediados nestas nações pioneiras sendo que os estudos de impactos ambientais passaram a ser elaborados a partir da década de 70, por causa das exigências do Banco Mundial, principalmente em projetos de construções de usinas hidrelétricas (ROCHA et al, 2005).

Somente na década de 80 que o país se atenta para a criação de leis em nível federal que vem abordando sobre a questão do licenciamento ambiental. Sendo a Lei Federal no 6.803/80, a primeira lei direcionada para o licenciamento ambiental no qual estabeleceu as diretrizes básicas para o zoneamento industrial nas áreas críticas de poluição (OLIVEIRA, 2012).

Contudo, o licenciamento ambiental é considerado efetivamente introduzido no ordenamento jurídico brasileiro com o advento da Lei Federal n. o 6.938/81, que dispôs sobre a Política Nacional de Meio Ambiente. No art. 9ㅇ, IV da referida Lei, o instituto do licenciamento ambiental é apontado como um dos instrumentos da Política Nacional de Meio Ambiente.

\begin{abstract}
“A lei no 6.938/81 também dispôs que o Sistema Nacional do Meio Ambiente que visa estabelecer um conjunto articulado e integrado, formado pelos órgãos e entidades da União, dos Estados, do Distrito Federal e dos Municípios, responsáveis pela proteção e melhoria da qualidade ambiental, com atribuições, regras e práticas específicas que se complementam" (BRASIL, 2009).
\end{abstract}

A ausência de licenciamento afeta de forma direta a vida e da população, contudo, no Brasil, percebese certa indiferença das autoridades públicas em relação à aplicação das sanções a quem comete este crime, prova disso é que somente em 12 de fevereiro de 1998, a Política Nacional do Meio Ambiente ganhou reforço com a Lei no 9.605/98 que dispõe sobre as sanções penais e administrativas lesivas ao meio ambiente, conhecida como Lei de Crimes Ambientais, esse instrumento especifica a magnitude do licenciamento no seu art. $54^{\circ}$, trazendo uma serie de obrigatoriedades visando combater os danos provocados pela falta de licenciamento, assim como suas sanções.

O licenciamento ambiental deve ser encarado como um instrumento de grande importância pelos empreendimentos brasileiros que precisam reconhecer sua responsabilidade no processo de degradação dos recursos naturais. Este trabalho tem como objetivo discutir teoricamente o processo de licenciamento ambiental em empreendimentos no estado de Sergipe. Neste artigo então discorrerá sobre a legislação federal e sobre os tipos de licenças para então debater se a legislação sergipana promove uma política ambiental eficaz.

\title{
METODOLOGIA
}

O artigo para alcançar o objetivo estabelecido caracteriza uma pesquisa de abordagem qualitativa visto que este tipo de abordagem segundo Oliveira (1999)

Possuem a facilidade de poder descrever a complexidade de determinada hipótese ou problema, analisar a interação de certas variáveis, compreender e classificar processos 
dinâmicos experimentados por grupos sociais, apresentar contribuições no processo de mudança, criação ou formação de opiniões.

A pesquisa qualitativa se mostrou imprescindível no que concerne a compreensão sobre os limites e possibilidades do processo de licenciamento ambiental, bem como todas as complexidades geradas pelo tema. Os procedimentos adotados neste trabalho foram à pesquisa documental e a pesquisa bibliográfica. 0 presente artigo fez uso de livros, artigos científicos, monografias, dissertações e teses realizadas sobre o tema, bem como utilizou acervos virtuais que contivessem informações pertinentes às questões do processo de licenciamento ambiental. Além de usar como as fontes principais aquelas disponíveis pelos órgãos oficiais que fazem o gerenciamento de tais informações como a Lei Federal n. 6.938/81 e Resolução CONAMA no 237.

\section{DISCUSSÃO TEÓRICA}

\section{Instrumentos Legais de Licenciamento no Brasil}

A legislação ambiental brasileira é reconhecida por muitos autores como uma das melhores do mundo, visto que regem as questões ambientais no âmbito da sua competência, normas e padrões compatíveis com o meio ambiente ecologicamente equilibrado e essencial qualidade de vida. A responsabilidade ambiental abrange o Poder Público e a coletividade na defesa dos recursos naturais utilizados e, as empresas brasileiras como maiores consumidores dessas riquezas, têm o dever de preserválas, assim garantidas pelo art. 225 da Constituição Federal (Câmara Neta et al., 2015).

No Brasil, o licenciamento ambiental constitui o procedimento administrativo mediante o qual um órgão ambiental governamental que tem a responsabilidade de liberar licença para implantação, a ampliação e a operação de empreendimentos possíveis causadores de degradação ambiental. O processo de licenciamento é efetivado perante um dos órgãos federais, estaduais ou municipais integrantes do SISNAMA (ARAÚJO et al., 2013).

O licenciamento ambiental, considerado um dos mais importantes mecanismos de controle, antecede a própria Constituição Federal de 1988. Como abordado anteriormente, o licenciamento ambiental foi criado pela Lei 6.938/81, que foi recepcionada pela carta magna, que inovou o conceito legal ao "estabelecer a competência ambiental comum dos entes federativos" (BRASIL, 2009).

As políticas e ações dos munícipios podem e devem estar associadas à "inúmeras possibilidades de interação entre os Estados e a União, compartilhando responsabilidades em condições de autonomia, cooperação e complementaridade" (BRASIL, 2009). No entanto, o fato é que os instrumentos legais de licenciamento ambiental são mais desenvolvidos e aplicados no âmbito da União e dos Estados, que assumem a responsabilidade dos munícipios sem órgão ambiental competente.

A assunção do papel constitucional por parte do município garante uma série de benefícios (BRASIL, 2009): (a) maior proximidade dos problemas a enfrentar e melhor acessibilidade dos usuários às políticas e serviços públicos; (b) maior adaptabilidade das políticas e programas às peculiaridades locais; (c) melhor utilização dos recursos e maior eficiência na implementação de ações e políticas; (d) maior visibilidade e 
transparência nas tomadas de decisões; e (e) efetiva democratização dos processos decisórios com a participação da população envolvida e melhoria das condições para negociação de conflitos.

A finalidade do licenciamento ambiental é de "promover o controle prévio à construção, instalação, ampliação e funcionamento de estabelecimentos e atividades utilizadoras de recursos ambientais, considerados efetiva e potencialmente poluidores, bem como os capazes, sob qualquer forma, de causar degradação ambiental" (BRASIL, 2009).

Na legislação federal, o licenciamento ambiental é regido primordialmente pelas seguintes normas legais: a Lei no 6.938/81, da Política Nacional do Meio Ambiente; a Resolução CONAMA no 001 , de 23 de janeiro de 1986, que estabelece as diretrizes gerais para elaboração do Estudo de Impacto Ambiental (ElA) e consequente Relatório de Impacto Ambiental (RIMA) nos processos de licenciamento ambiental sendo que segundo Guerra e outros colaboradores (2009) impacto ambiental seriam ações que promovem a alteração do meio ambiente ou em parte dele sendo que qualquer alteração das propriedades físico-química e biológicas do meio ambiente causada por qualquer forma de matéria ou energia resultante das atividades humanas.

Além dessas leis no âmbito federal, a Resolução no 237, de 19 de dezembro de 1997, estabelece procedimentos e critérios, e reafirma os princípios de descentralização previstos na Política Nacional de Meio Ambiente e na Constituição Federal de 1988 (BRASIL, 2009). Nos Estados, o licenciamento ambiental é regido por legislação específica, com ou sem complementos, que podem ou não trazer inovações frente à legislação federal.

O processo de licenciamento ambiental foi acolhido e normatizado pelo CONAMA (Conselho Nacional do Meio Ambiente), que editou resoluções relacionadas: (a) Resolução no 237/1997, que determina os tipos de empreendimentos ou atividades estão sujeitos ao processo de licenciamento ambiental; (b) Resolução no 001/1986, que determina os tipos de empreendimentos ou atividades que devem obrigatoriamente apresentar EIA (Estudo de Impacto Ambiental) e RIMA (Relatório de Impacto Ambiental) no processo de licenciamento; (c) Resolução no 009/1987, que determina quando deve ser efetivada a realização de audiência pública no processo de licenciamento; (d) Resolução no 006/1986, que determina quais medidas devem ser adotadas para garantir a publicidade de todo o processo de licenciamento ambiental.

A legislação federal acolheu ainda o processo de licenciamento através da edição da Lei Complementar no 140/2011 que abordou as competências de licenciamento, determinando os casos onde o processo deverá ser pela União, Estados, Distrito Federal ou municípios. Por conta disto, cada Estado brasileiro editou normas específicas.

\section{Tipos de Licença e suas Características}

Licença ambiental é o ato administrativo resultante do processo de licenciamento, onde o órgão ambiental competente define "condições, restrições e medidas de controle ambiental que deverão ser obedecidas pelo empreendedor, pessoa física ou jurídica, para localizar, instalar, ampliar e operar empreendimentos ou atividades utilizadoras dos recursos ambientais consideradas efetiva ou 
potencialmente poluidoras ou aquelas que, sob qualquer forma, possam causar degradação ambiental" (BRASIL, 2009). As licenças ambientais no Brasil, a luz da legislação federal e dos normativos do CONAMA, são classificadas em Licença Prévia, Licença de Implantação, e Licença de Operação.

Compreende-se como etapas de um empreendimento: planejamento; instalação; e operação. Segundo normas estabelecidas no Decreto 99.274/90, que regulamenta a Lei 6.938/81, e detalhadas na Resolução CONAMA no 237 de 1997, cada fase tem uma licença específica.

A licença prévia (LP) trata da fase preliminar, ou seja, do planejamento do empreendimento ou atividade, versando sobre sua localização e concepção, e garantindo a viabilidade ambiental e as condicionantes e compensações das próximas fases de sua implementação. Na LP não é permitido quaisquer tipos de obra ou alterações no sistema licenciado.

A licença de implantação permite a instalação da atividade ou empreendimento em consonância com as características e informações constantes dos programas e projetos aprovados. Esta licença deve incluir medidas de controle ambiental e demais condicionantes, relacionadas ao objetivo do pedido.

A licença de operação libera a operação do empreendimento ou atividade, após o efetivo cumprimento das duas licenças anteriores, no tocante às condicionantes e compensações. Os Estados e municípios podem criar outros tipos de licença para empreendimentos diferenciados. Alguns Estados brasileiros mantém o padrão da legislação federal emitindo apenas LP, LI e LO. As atividades sujeitas ao licenciamento ambiental estão dispostas no Quadro 01.

Quadro 01: Atividades ou empreendimentos sujeitos ao licenciamento ambiental.

\begin{tabular}{|c|c|}
\hline Extração e tratamento de minerais & $\begin{array}{l}\text { - Pesquisa mineral com guia de utilização; } \\
\text { - Lavra a céu aberto, inclusive de aluvião, com ou sem beneficiamento; } \\
\text { - Lavra subterrânea com ou sem beneficiamento; } \\
\text { - Lavra garimpeira; } \\
\text { - Perfuração de poços e produção de petróleo e gás natural. }\end{array}$ \\
\hline $\begin{array}{l}\text { Indústria de produtos minerais não } \\
\text { metálicos }\end{array}$ & $\begin{array}{l}\text { - Beneficiamento de minerais não metálicos, não associados à extração; } \\
\text { - Fabricação e elaboração de produtos minerais não metálicos tais como: produção de } \\
\text { material cerâmico, cimento, gesso, amianto e vidro, entre outros. }\end{array}$ \\
\hline Indústria metalúrgica & $\begin{array}{l}\text { - Fabricação de aço e de produtos siderúrgicos; } \\
\text { - Produção de fundidos de ferro e aço / forjados / arames / relaminados com ou sem } \\
\text { tratamento de superfície, inclusive galvanoplastia; } \\
\text { - Metalurgia dos metais não-ferrosos, em formas primárias e secundárias, inclusive ouro; } \\
\text { - Produção de laminados / ligas / artefatos de metais não-ferrosos com ou sem tratamento } \\
\text { de superfície, inclusive galvanoplastia; } \\
\text { - Relaminação de metais não-ferrosos, inclusive ligas; } \\
\text { - Produção de soldas e anodos; } \\
\text { - Metalurgia de metais preciosos; } \\
\text { - Metalurgia do pó, inclusive peças moldadas; } \\
\text { - Fabricação de estruturas metálicas com ou sem tratamento de superfície, inclusive } \\
\text { galvanoplastia; } \\
\text { - Fabricação de artefatos de ferro / aço e de metais não-ferrosos com ou sem tratamento } \\
\text { de superfície, inclusive galvanoplastia; } \\
\text { - Têmpera e cementação de aço, recozimento de arames, tratamento de superfície. }\end{array}$ \\
\hline Indústria mecânica & $\begin{array}{l}\text { - Fabricação de máquinas, aparelhos, peças, utensílios e acessórios com e sem tratamento } \\
\text { térmico e/ou de superfície. }\end{array}$ \\
\hline $\begin{array}{l}\text { Indústria de material elétrico, } \\
\text { eletrônico e comunicações }\end{array}$ & $\begin{array}{l}\text { - Fabricação de pilhas, baterias e outros acumuladores; } \\
\text { - Fabricação de material elétrico, eletrônico e equipamentos para telecomunicação e } \\
\text { informática; } \\
\text { - Fabricação de aparelhos elétricos e eletrodomésticos. }\end{array}$ \\
\hline Indústria de material de transporte & $\begin{array}{l}\text { - Fabricação e montagem de veículos rodoviários e ferroviários, peças e acessórios; } \\
\text { - Fabricação e montagem de aeronaves; } \\
\text { - Fabricação e reparo de embarcações e estruturas flutuantes. }\end{array}$ \\
\hline
\end{tabular}




\begin{tabular}{|c|c|}
\hline Indústria de madeira & $\begin{array}{l}\text { - Serraria e desdobramento de madeira; } \\
\text { - Preservação de madeira; } \\
\text { - Fabricação de chapas, placas de madeira aglomerada, prensada e compensada; } \\
\text { - Fabricação de estruturas de madeira e de móveis. }\end{array}$ \\
\hline Indústria de papel e celulose & $\begin{array}{l}\text { - Fabricação de celulose e pasta mecânica; } \\
\text { - Fabricação de papel e papelão; } \\
\text { - Fabricação de artefatos de papel, papelão, cartolina, cartão e fibra prensada. }\end{array}$ \\
\hline Indústria de borracha & $\begin{array}{l}\text { - Beneficiamento de borracha natural; } \\
\text { - Fabricação de câmara de ar e fabricação e recondicionamento de pneumáticos; } \\
\text { - Fabricação de laminados e fios de borracha; } \\
\text { - Fabricação de espuma de borracha e de artefatos de espuma de borracha, inclusive látex. }\end{array}$ \\
\hline Indústria de couros e peles & $\begin{array}{l}\text { - Secagem e salga de couros e peles; } \\
\text { - Curtimento e outras preparações de couros e peles; } \\
\text { - Fabricação de artefatos diversos de couros e peles; } \\
\text { - Fabricação de cola animal. }\end{array}$ \\
\hline Indústria química & $\begin{array}{l}\text { - Produção de substâncias e fabricação de produtos químicos; } \\
\text { - Fabricação de produtos derivados do processamento de petróleo, de rochas betuminosas } \\
\text { e da madeira } \\
\text { - Fabricação de combustíveis não derivados de petróleo; } \\
\text { - Produção de óleos/gorduras/ceras vegetais-animais/óleos essenciais vegetais e outros } \\
\text { produtos da destilação da madeira; } \\
\text { - Fabricação de resinas e de fibras e fios artificiais e sintéticos e de borracha e látex } \\
\text { sintéticos; } \\
\text { - Fabricação de pólvora/explosivos/detonantes/munição para caça-desporto, fósforo de } \\
\text { segurança e artigos pirotécnicos; } \\
\text { - Recuperação e refino de solventes, óleos minerais, vegetais e animais; } \\
\text { - Fabricação de concentrados aromáticos naturais, artificiais e sintéticos; } \\
\text { - Fabricação de preparados para limpeza e polimento, desinfetantes, inseticidas, germicidas } \\
\text { e fungicidas; } \\
\text { - Fabricação de tintas, esmaltes, lacas, vernizes, impermeabilizantes, solventes e secantes; } \\
\text { - Fabricação de fertilizantes e agroquímicos; } \\
\text { - Fabricação de produtos farmacêuticos e veterinários; } \\
\text { - Fabricação de sabões, detergentes e velas; } \\
\text { - Fabricação de perfumarias e cosméticos; } \\
\text { - Produção de álcool etílico, metanol e similares. }\end{array}$ \\
\hline $\begin{array}{l}\text { Indústria de produtos de matéria } \\
\text { plástica }\end{array}$ & $\begin{array}{l}\text { - Fabricação de laminados plásticos; } \\
\text { - Fabricação de artefatos de material plástico. }\end{array}$ \\
\hline $\begin{array}{l}\text { Indústria têxtil, de vestuário, } \\
\text { calçados e artefatos de tecidos }\end{array}$ & $\begin{array}{l}\text { - Beneficiamento de fibras têxteis, vegetais, de origem animal e sintéticos; } \\
\text { - Fabricação e acabamento de fios e tecidos; } \\
\text { - Tingimento, estamparia e outros acabamentos em peças do vestuário e artigos diversos } \\
\text { de tecidos; } \\
\text { - Fabricação de calçados e componentes para calçados. }\end{array}$ \\
\hline $\begin{array}{l}\text { Indústria de produtos alimentares } \\
\text { e bebidas }\end{array}$ & $\begin{array}{l}\text { - Beneficiamento, moagem, torrefação e fabricação de produtos alimentares; } \\
\text { - Matadouros, abatedouros, frigoríficos, charqueados e derivados de origem animal; } \\
\text { - Fabricação de conservas; } \\
\text { - Preparação de pescados e fabricação de conservas de pescados; } \\
\text { - Preparação, beneficiamento e industrialização de leite e derivados; } \\
\text { - Fabricação e refinação de açúcar; } \\
\text { - Refino / preparação de óleo e gorduras vegetais; } \\
\text { - Produção de manteiga, cacau, gorduras de origem animal para alimentação; } \\
\text { - Fabricação de fermentos e leveduras; } \\
\text { - Fabricação de rações balanceadas e de alimentos preparados para animais; } \\
\text { - Fabricação de vinhos e vinagre; } \\
\text { - Fabricação de cervejas, chopes e maltes; } \\
\text { - Fabricação de bebidas não alcoólicas, bem como engarrafamento e gaseificação de águas } \\
\text { minerais; } \\
\text { - Fabricação de bebidas alcoólicas. }\end{array}$ \\
\hline Indústria de fumo & $\begin{array}{l}\text { - Fabricação de cigarros/charutos/cigarrilhas e outras atividades de beneficiamento do } \\
\text { fumo. }\end{array}$ \\
\hline Indústrias diversas & $\begin{array}{l}\text { - Usinas de produção de concreto; } \\
\text { - Usinas de asfalto; } \\
\text { - Serviços de galvanoplastia. }\end{array}$ \\
\hline Obras civis & $\begin{array}{l}\text { - Rodovias, ferrovias, hidrovias, metropolitanos; } \\
\text { - Barragens e diques; } \\
\text { - Canais para drenagem; } \\
\text { - Retificação de curso de água; } \\
\text { - Abertura de barras, embocaduras e canais; }\end{array}$ \\
\hline
\end{tabular}




\begin{tabular}{|c|c|}
\hline & $\begin{array}{l}\text { - Transposição de bacias hidrográficas; } \\
\text { - Outras obras de arte. }\end{array}$ \\
\hline Serviços de utilidade & $\begin{array}{l}\text { - Produção de energia termoelétrica; } \\
\text { - Transmissão de energia elétrica; } \\
\text { - Estações de tratamento de água; } \\
\text { - Interceptores, emissários, estação elevatória e tratamento de esgoto sanitário; } \\
\text { - Tratamento e destinação de resíduos industriais (líquidos e sólidos); } \\
\text { - Tratamento/disposição de resíduos especiais tais como: de agroquímicos e suas } \\
\text { embalagens usadas e de serviço de saúde, entre outros; } \\
\text { - Tratamento e destinação de resíduos sólidos urbanos, inclusive aqueles provenientes de } \\
\text { fossas; } \\
\text { - Dragagem e derrocamentos em corpos d'água; } \\
\text { - Recuperação de áreas contaminadas ou degradadas. }\end{array}$ \\
\hline Transporte, terminais e depósitos & $\begin{array}{l}\text { - Transporte de cargas perigosas; } \\
\text { - Transporte por dutos; } \\
\text { - Marinas, portos e aeroportos; } \\
\text { - Terminais de minério, petróleo e derivados e produtos químicos; } \\
\text { - Depósitos de produtos químicos e produtos perigosos. }\end{array}$ \\
\hline Turismo & - Complexos turísticos e de lazer, inclusive parques temáticos e autódromos. \\
\hline Atividades diversas & $\begin{array}{l}\text { - Parcelamento do solo; } \\
\text { - Distrito e polo industrial. }\end{array}$ \\
\hline Atividades agropecuárias & $\begin{array}{l}\text { - Projeto agrícola; } \\
\text { - Criação de animais; } \\
\text { - Projetos de assentamentos e de colonização. }\end{array}$ \\
\hline Uso de recursos naturais & $\begin{array}{l}\text { - Silvicultura; } \\
\text { - Exploração econômica da madeira ou lenha e subprodutos florestais; } \\
\text { - Atividade de manejo de fauna exótica e criadouro de fauna silvestre; } \\
\text { - Utilização do patrimônio genético natural; } \\
\text { - Manejo de recursos aquáticos vivos; } \\
\text { - Introdução de espécies exóticas e/ou geneticamente modificadas; } \\
\text { - Uso da diversidade biológica pela biotecnologia. }\end{array}$ \\
\hline
\end{tabular}

Fonte: Anexo 1 da Resolução CONAMA no 237/97.

\section{Licenciamento Ambiental no Estado de Sergipe}

No âmbito estadual, em Sergipe, o órgão que e responsável pelo licenciamento é a Administração Estadual do Meio Ambiente (ADEMA), autarquia criada pela Lei 2.181 de 12 de outubro de 1978, vinculada à Secretaria de Estado do Meio Ambiente e dos Recursos Hídricos (SEMARH), que analisa e emite parecer técnico referente ao projeto apresentado pelo empreendedor.

Compete ao órgão Ambiental Estadual (ADEMA), promover a preservação do meio ambiente, da fauna, da flora e do uso racional dos recursos hídricos, assim como proteção dos ecossistemas naturais (SERGIPE, 1978). A organização básica do órgão estadual foi definida pela lei nำ5. 057 de 07 de novembro de 2003 e modificou o seu status para autarquia especial através da lei no 6650 de 30 de junho de 2009 (SERGIPE, 2003; SERGIPE, 2009).

A ADEMA atua subordinada a legislação federal e às resoluções do CONAMA assim como também às resoluções normativas do Conselho Estadual do Meio Ambiente (CEMA), órgão deliberativo no estado de Sergipe, que regulamenta os processos de licenciamento ambiental através da resolução 006/2008 de 29 de julho de 2008 (SERGIPE, 2008).

Esta resolução institui que os procedimentos administrativos do licenciamento ambiental, os critérios de enquadramento e tipificação das atividades e empreendimentos potencialmente causadores da degradação ambiental, bem como critérios de remuneração dos custos operacionais e de análise das Licenças Ambientais e Autorizações estão a cargo da ADEMA. 
No estado de Sergipe estão sujeitos ao licenciamento ambiental a construção, instalação, ampliação, modificação e funcionamento de estabelecimentos, empreendimentos, obras e atividades utilizadoras de recursos ambientais, considerados efetiva e/ou potencialmente poluidores, bem como os capazes, sob qualquer forma, de causar degradação ambiental sendo que os empreendimentos estão listados no anexo I do documento (SERGIPE, 2008).

Segundo Melo (2012) a resolução de 2008 tentou modernizar a estrutura administrativa e funcional da ADEMA com a obtenção de um sistema de informatização que pudesse favorecer a otimização e celeridade do processamento do licenciamento ambiental. O sistema de informatização homologado foi o Cerberus, o qual foi desenvolvido pelo Centro de Recursos Ambientais (CRA), órgão ambiental do estado da Bahia no final do ano de 1999 (XAVIER et al., 2012).

Quadro 02: Processos técnicos de licenciamento formados no Cerberus.

\begin{tabular}{l|rrrr|r}
\hline \multicolumn{1}{c|}{ Tipos de processos formados } & $\mathbf{2 0 0 8}$ & $\mathbf{2 0 0 9}$ & $\mathbf{2 0 1 0}$ & $\mathbf{2 0 1 1}$ & $\mathbf{2 0 0 8 - 2 0 1 1}$ \\
\hline Autorização Ambiental AA & 12 & 114 & 158 & 241 & 525 \\
Autorização de Desmate - AD & 0 & 11 & 41 & 51 & 103 \\
Averbação de Reserva Legal - ARL & 22 & 115 & 68 & 141 & 346 \\
Certificado de Dispensa de Licença - CDL & 0 & 9 & 342 & 196 & 547 \\
Licença de Instalação - LI & 233 & 329 & 421 & 348 & 1331 \\
Licença de Instalação e Operação-LIO & 13 & 25 & 1 & 35 & 74 \\
Licença de Operação-LO & 298 & 360 & 366 & 346 & 1370 \\
Licença Prévia - LP & 330 & 435 & 297 & 286 & 1348 \\
Licença Prévia de Perfuração-LPPer & 52 & 63 & 75 & 67 & 257 \\
Licença Prévia de Produção-LPPro & 8 & 8 & 4 & 5 & 25 \\
Licença Simplificada - LS & 0 & 77 & 288 & 368 & 733 \\
Licença Única - LU & 0 & 14 & 45 & 23 & 82 \\
Renovação de Licença de Instalação-RLI & 82 & 114 & 177 & 229 & 602 \\
Renovação de Licença de Operação-RLO & 286 & 252 & 308 & 418 & 1264 \\
Renovação de Licença Prévia - RLP & 9 & 67 & 46 & 57 & 179 \\
\hline \multicolumn{1}{c}{ Total } & $\mathbf{1 3 4 5}$ & $\mathbf{1 9 9 3}$ & $\mathbf{2 6 3 7}$ & $\mathbf{2 8 1 1}$ & $\mathbf{8 7 8 6}$
\end{tabular}

Fonte: Xavier (2002).

A implantação do sistema Cerberus favoreceu a rastreabilidade dos processos formados na ADEMA. A rastreabilidade do sistema é uma forma de verificar quantos processos foram formados na ADEMA em um determinado período. Xavier e colaboradores (2012) fizeram um estudo em sobre esse sistema desde o início do funcionamento do Cerberus no dia 10/03/2008 até a data de 30/12/2011, ou seja, 03 anos, 09 meses e 20 dias de operação, foram formados 21.582 processos, sendo 4.302 administrativos, 14.758 técnicos e 2.522 de demanda judicial. No Quadro 02 o autor demonstra que foram criados 8.786 processos no período de 2008 a 2011.

Pode- se observar com os dados acima que houve crescimento no número de pedidos solicitando o licenciamento ambiental na ADEMA, refletindo assim uma maior busca pelos empreendimentos de ter regularização perante o órgão ambiental. A implantação de um sistema de informação em uma organização tende a propiciar a melhoria nos serviços por ela prestados, pela agilidade e confiabilidade na execução de suas atividades.

Segundo Xavier (2012) o sistema Cerberus culminou na melhoria do processo de licenciamento ambiental e foi um dos principais avanços na gestão do meio ambiente no Estado de Sergipe nos últimos anos. Além de que a legislação no âmbito estadual segue as normas das leis federais, o CEMA instituiu a 
resolução 006/008 para que a estrutura e o funcionamento dos processos de licenciamento ambiental sejam mais rápidos e eficientes.

\section{CONCLUSÕES}

A legislação ambiental do Brasil busca o desenvolvimento econômico, mas tendo em vista a minimização dos impactos ambientais provocados pelos empreendimentos. Então mediante os esforços dos órgãos ambientais em regulamentar o direito ao meio ambiente nada adianta a aplicação de uma legislação ambiental rigorosa quando não existe a consciência de que é essencial a preservação do meio ambiente para a vida das atuais e futuras gerações.

Neste contexto, o artigo tentou discutir a legislação ambiental com enfoque no estado de Sergipe sendo que não pode ser negada a tentativa e os esforços do CEMA através da resolução 006/2008 de superar as falhas e carências presentes no ADEMA visto que o Conselho Estadual que tem por finalidade, assessorar o Governo do Estado na formulação de uma política ambiental, propondo diretrizes para o meio ambiente e editando normas e padrões compatíveis com o meio ambiente ecologicamente equilibrado e essencial à qualidade de vida.

É importante ressaltar que o ADEMA é um órgão estadual e sua legislação baseia-se na legislação federal para atuar na política de preservação do meio ambiente na qual o ADEMA recebe uma demanda de licitação de todo o estado, e foi essencial a implantação de um sistema que pudesse facilitar para os empreendimentos os pedidos dos processos de licenciamento ambiental.

\section{REFERÊNCIAS}

ARAÚJO, S. M. V. G.; ROMA, J. C.; PÊGO, B.. Licenciamento ambiental: base normativa e perspectivas. In: IPEA Licenciamento ambiental para o desenvolvimento urbano: avaliação de instrumentos e procedimentos. Rio de Janeiro: IPEA, 2013.

BRASIL. Ministério do Meio Ambiente. Programa Nacional de Capacitação de Gestores Ambientais: caderno de licenciamento ambiental. Brasília: MMA, 2009.

BRASIL. Lei no 9.605 de 1998. Dispõe sobre as sanções penais e administrativas derivadas de condutas e atividades lesivas ao meio ambiente, e dá outras providências. Brasília: DOU, 1998.

BRASIL. Lei 6.938 de 1981. Dispõe sobre a Política Nacional do Meio Ambiente, seus fins e mecanismos de formulação e aplicação, e dá outras providências. Brasília: DOU, 1981.

BRASIL. Conselho Nacional do Meio Ambiente, Resolução CONAMA no 237 de 1997. Dispõe sobre a revisão e complementação dos procedimentos e critérios utilizados para o licenciamento ambiental. Brasília: DOU, 1997.

GUERRA, A. J. T. ; SILVA, C. E. ; MORGADO, C. R. V. ; SANTOS, F. A. D. ; ARAÚJO, G. H. S. ; ALMEIDA, J. R. ; AGUIAR, L. A. ; SÁ, M. F. P. ; GARCIA, P. A. A. ; FERMAM, R. K. S. ; VIEIRA, R. P. ; ALMEIDA, S. M. . Dicionário de Meio Ambiente. Rio de Janeiro: Thex, 2009.
MELO, J. D.. Gestão do conhecimento e apoio a decisão na gestão ambiental: Case Based Reasoning aplicado ao licenciamento ambiental. Dissertação (Mestrado em Modelagem Computacional de Conhecimento) Universidade Federal de Alagoas, Maceió, 2012.

CÂMARA NETA, M. S.; MOURA, K. C. F.; DIAS, N. S.; SOUZA, A. C. M.; MOURA, K. H. S.. Licenciamento ambiental: Conflito de interesses. Revista Verde de Agroecologia e Desenvolvimento Sustentável, v.10, n.5, p.76-80, 2015.

OLIVEIRA, C. M. F. V.. Licenciamento ambiental. Monografia (Especialização em Direito Ambiental) - Universidade Federal do Rio Grande do Sul, Porto Alegre, 2012.

ROCHA, E. C.. Avaliação de impactos ambientais nos países do Mercosul. Ambiente \& Sociedade, v.8, n.2, p.20-21, 2005.

SERGIPE. Lei no 2.181, 12 de outubro de 1978. Autoriza o Poder Executivo a criar a Administração Estadual do Meio Ambiente, sob a forma de autarquia estadual, e dá outras providências. Aracaju: DOE, 1978.

Sergipe. Lei no 5.057, de 07 de novembro de 2003. Dispõe sobre a organização básica da Administração Estadual. Aracaju: DOE, 2003. 
SERGIPE. Lei no 6.650, de 30 de junho de 2009. Dispõe sobre o recebimento de status de autarquia especial. Aracaju: DOE, 2009

SERGIPE. Conselho Estadual do Meio Ambiente. Resolução no 06, de 29 de julho de 2008. Dispõe sobre procedimentos administrativos do licenciamento ambiental, critérios de enquadramento e tipificação de atividades e empreendimentos potencialmente causadores da degradação ambiental e fixação de custos operacionais e de análise das licenças ambientais e autorizações. Aracaju: COMA, 2008.
XAVIER, U. R.. Informatização do licenciamento ambiental na ADEMA: consequências da implantação do sistema Cerberus. In: CONGRESSO NORTE-NORDESTE DE INOVAÇÃO, 7. Anais. Palmas: IFTO, 2012.

SOBRINHO, C. A.. A falácia do desenvolvimento sustentável: uma análise a partir da sociedade de consumo. Tese (Doutorado em Ciências sociais) - Universidade Estadual Paulista, Marília, 2016.

A CBPC - Companhia Brasileira de Produção Científica (CNPJ: 11.221.422/0001-03) detém os direitos materiais desta publicação. Os direitos referem-se à publicação do trabalho em qualquer parte do mundo, incluindo os direitos às renovações, expansões e disseminações da contribuição, bem como outros direitos subsidiários. Todos os trabalhos publicados eletronicamente poderão posteriormente ser publicados em coletâneas impressas sob coordenação da Sapientiae Publishing, da Companhia Brasileira de Produção Científica e seus parceiros autorizados. Os (as) autores (as) preservam os direitos autorais, mas não têm permissão para a publicação da contribuição em outro meio, impresso ou digital, em português ou em tradução. 